\title{
Vivir en su luz \\ (el significado del Tú no humano desde la filosofía de Buber)
}

\section{To Live in its Light (Thinking the Meaning of Non-human Thou from Buber's Philosophy Point of View)}

\author{
Adriana Menassé \\ Instituto de Filosofía \\ Universidad Veracruzana
}

\begin{abstract}
Resumen: ¿Cuál es el significado del Tú no humano en la filosofía de Buber? ¿Qué significa incluir en la relación fundamental Yo-Tú la relación con los árboles y los animales - por no hablar de la relación con los objetos y las obras de arte-? A través de la interpretación de este aspecto polémico de la filosofía buberiana - el de la relación fundante con entidades no humanas - el presente ensayo quiere sugerir que detrás del planteamiento cuasi panteísta de Buber se encuentra un núcleo ético y espiritual de enorme repercusión para la manera en la que comprendemos la estructura misma de nuestra condición. Dicha estructura estaría marcada por una doble vinculación constitutiva: una que tiene su anclaje en la relación con el otro ser humano y mira hacia la ética, y otra que entrega su adhesión y fidelidad a la vida en lo que ésta tiene de donación y milagro. Estas dos hebras indisolublemente entrelazadas sostienen y renuevan el amor que el ser humano aporta a la existencia desnuda, y que está llamado a sostener con sus actos diariamente.
\end{abstract}

\begin{abstract}
What is the meaning of the non-human Thou in Buber's philosophy? What is Buber getting at when he makes trees and animals part of the fundamental relationship I-Thou? We would like to show that, more than a pantheistic view, what is at stake is a more complex understanding of the transcendental binding that constitutes our human condition. This double binding has to do with the love and the ethical responsibility that is brought about by the I-Thou encounter and is expressed through actions of lovingkindness; at the same time this spiritual movement expands beyond human dialogue and is transformed into a radical assertion of life itself. These two strands of our ontological making intertwine in order to introduce love into sheer existence, a love we are prone to uphold through our everyday actions.
\end{abstract}

Palabras Clave: yo-tú, naturaleza, gratitud.

KEYWORDS: I-Thou, nature, thankfulness.

RECIBIDO: 5 de febrero de 2016 • ACEPTADO: 21 de abril de 2016 


\section{Adriana Menassé \\ Instituto de Filosofía \\ Universidad Veracruzana \\ Vivir en su luz (el significado del Tú no humano desde la filosofía de Buber)}

1.

¿Cuál es el significado del Tú no humano en la filosofía de Buber? ¿Qué significa incluir en la relación fundamental Yo-Tú la relación con los árboles y los animales - por no hablar de la relación con los objetos y las obras de arte - ? Quisiera abordar la rica obra de este autor para desentrañar el movimiento espiritual que conforma su pensamiento. ¿Qué indicios nos aporta para comprender la crisis de nuestro tiempo y calibrar la aventura humana en toda su envergadura y profundidad? Abordo la cuestión desde un pensamiento de raíz judía, y exploro lo que este venero ofrece para hacer frente a las graves interrogantes de nuestro tiempo.

Como es sabido, Martin Buber es conocido principalmente por introducir a la discusión filosófica el pensamiento dialógico, es decir, por poner en el centro de la reflexión la estructura relacional de la condición humana. En la línea de pensamiento abierta por Kierkegaard, Buber plantea un movimiento de ruptura respecto a la tradición centrada en el conocimiento y búsqueda de la verdad, pero a diferencia del primero propone una antropología basada en el encuentro con los demás y con el mundo. El Tú de la relación Yo-Tú constituye el encuentro definitivo, el que funda nuestra persona al interrumpir la homogeneidad de las re- 
laciones instrumentales (eso que el autor llama nuestra relación Yo-eso tanto con el mundo como con los otros) para llamarnos a la presencia plena del encuentro. La relación Yo-Tú es el verdadero troquel en que se acuña nuestra subjetividad como respuesta a ese otro que nos nombra. Recibimos la vida de los otros; no sólo la vida biológica que es necesariamente una donación, sino la vida humanizada, inscripción en el lenguaje y en el amor. La relación Yo-Tú transforma nuestra precariedad en apertura y vínculo. ${ }^{1}$

No es Buber el único exponente de esta rica vertiente del pensamiento que tan fructífera se ha mostrado: en la tradición del pensamiento judío, Franz Rosenzweig ha trazado y despejado el camino y Emmanuel Levinas, al lado de un sinnúmero de pensadores que siguen sus pasos, ha hecho contribuciones importantísimas. El Otro nos constituye como sujetos. Y, aunque Buber habla de reciprocidad, Levinas de asimetría y Rosenzweig del paso de uno a otro de los elementos básicos de nuestro estar en el mundo, en un análisis podemos encontrar más puntos de contacto que diferencias de fondo. En la medida en que la relación con el otro constituye un punto de ruptura respecto a la supervivencia desnuda y un guiño de amistad, el mundo se constituye como diálogo. La pregunta es, entonces, ¿quién llama?

¿Quién llama, en verdad? Aquí empezamos a encontrar algunos matices de diferencias importantes entre, por ejemplo, Buber y Levinas. No es mi intención hacer un estudio comparativo entre estos autores, pero, como se ha dicho, son tantos los aspectos afines, que resulta casi inevitable apuntar someramente sus desacuerdos. Es sobre todo en estos desacuerdos donde encontramos el sello de sus respectivas propuestas y de su visión. Considero aquí solamente el punto nodal de su disputa porque servirá, me parece, para echar luz sobre el tema que hoy nos convoca. En esta línea de reflexión, entonces, diríamos que si para Levinas llama ante todo el otro ser humano desde la altura de su desamparo radical, si la infinitud de Dios, digamos, nos es sólo accesible a través de la muda exhortación del rostro de ese prójimo que me dirige la voz o la mirada, en Buber parece ser Dios quien llama en primer término a través de diferentes vías. Y aunque la cuestión podría parecer casi retórica, sus

$1 \quad$ Cf. Buber 2006. 
implicaciones trazan la riqueza de su diálogo fallido. ¿Habla mi prójimo que lleva la marca de la trascendencia de Dios en el mandamiento que me impone, o habla la benevolencia de Dios que se hace presente a través de otros hombres y, en última instancia, de todos los seres?2

Me parece importante advertir que cuando Buber habla de Dios no está pensando en el Dios de la teología, no está pensando en una sustancia divina o en una presencia fáctica y vigilante. De hecho, preguntar por la existencia de Dios es imposible pues el cuestionamiento corta de entrada la realidad del vínculo. Le hablamos a Dios, no discurrimos sobre su existencia. Por eso Buber se refiere a Él como a una persona, como a una presencia capaz de establecer una relación viva e íntima con los seres humanos, y no como la representación abstracta de un principio (Buber 2006: 118-119). Ahora bien, si el Tú es el contacto definitivo, ese contacto personal y fundante cuyo paradigma es la relación del hombre con Dios y del hombre con su semejante, ¿cómo es que lo reconoce también en el vínculo con los árboles y los animales? ¿Cómo es que Buber extiende este privilegio a la naturaleza y a las cosas? ¿No es esto una concesión animista y panteísta que en cierto sentido contradice el principio fundamental del monoteísmo? Consideramos que para comprender la dimensión plena del pensamiento de este autor, será necesario dilucidar el horizonte de estas afirmaciones. Más que desestimarlas como exabrupto, quisiéramos entrever en ellas el sentido más amplio de su invitación.

El tema de las entidades no humanas como formas del diálogo fundamental ha suscitado algunas de las polémicas más constantes con la obra poético-filosófica de Martin Buber: si bien la relación con el otro ser humano ofrece la posibilidad privilegiada de constituir una vida significante, no es ésta, en absoluto, la única. Existen otras vías de acceso al Tú, nos dice este autor, otras maneras en las que el encuentro Yo-Tú trenza nuestra existencia. Dice Buber:

2 Véase, para estos puntos de comparación, la obra de Franz Rosenzweig La estrella de la redención, y El libro del sentido común sano y enfermo (Rosenzweig 2007 y 2001). Véase también la obra central de Emmanuel Levinas Totalidad e infinito, el grupo de entrevistas que le hace Phillipe Nemo en Ética e infinito, además de La huella del otro (Levinas 1982, 1999 y 2005), así como, en general, toda la obra de este autor. 
Tres son las esferas en que se construye el mundo de la relación.

La primera es la de la convivencia con la naturaleza, en la que la relación se mantiene en el umbral del lenguaje.

La segunda es la de la convivencia con los seres humanos, en la que adquiere la forma de lenguaje.

La tercera es la de la convivencia con los seres espirituales, en la que se carece de lenguaje, pero lo crea (Buber 2006: 91).

Cuando el autor habla de "seres espirituales" no está pensando en ángeles o entidades suprahumanas, está pensando en los escritos cardinales y en las obras de arte que acompañan nuestra vida. Es cierto que Buber es un hombre religioso y su filosofía está imbuida de un humor religioso en sentido amplio. Sabemos también que mucho de su formación la debe al jasidismo y, en algún sentido, a la cábala. No hay, sin embargo, en su trabajo ningún presupuesto dogmático, ni sobre la existencia de Dios ni sobre las formas de la fe. Hay sólo el intento de discernir el sentido y la manera en la que el encuentro con el otro ser humano y con el Tú en sus distintas manifestaciones transforman, para el hombre, la inmensidad indiferente en un espacio de sentido, el mundo en el milagro de la creación. La existencia de Dios es indemostrable, dice, pero la relación que establece con nosotros constituye nuestra certeza más profunda. ${ }^{3}$ Del hecho de presumir la existencia de vías no humanas hacia el Tú provienen algunos de los tenaces desencuentros con sus críticos, particularmente con Levinas, el otro gran pensador de la alteridad. ¿Pero qué es lo que en última instancia conforma la visión de Buber?

A lo largo del tiempo, Levinas cambió su actitud y el aprecio que tenía por el hombre a quien termina reconociendo como precursor y maestro, pero nunca dejó de señalar que la diferencia principal con $\mathrm{Bu}-$ ber residía en la noción de reciprocidad que está en la base del encuentro Yo-Tú en su filosofía. El cuestionamiento que le hace el lituano en "Objeciones y respuesta", rehúye la acusación de panteísmo para abordar el tema a partir de las implicaciones éticas que tiene, en su consideración, esa dimensión de reciprocidad en el encuentro con el Tú. Dice:

Si le objetamos a Buber el haber extendido el yo-tú a las cosas, no es porque nos resulte demasiado animista en su relación con la naturaleza,

3 Cf. Buber 2006: 120. 
sino porque nos parece demasiado artista en su relación con los hombres (Friedman 2006: 50).

"Demasiado artista" apunta al hecho de que en Buber el deslumbramiento de belleza y amor que le producen la naturaleza y las obras de arte, resulta en principio equivalente al encuentro con otro ser humano. Ambos constituyen un encuentro fundamental, el encuentro de un YoTú que apunta al reconocimiento y la fusión. Para Levinas, en cambio, la reciprocidad, esa horizontalidad de la relación primaria que propone Buber, pone en riesgo el carácter obligatorio y absoluto de la ética, pues sólo la separación entre ellos, entre yo y el otro, revela la trascendencia de la obligación moral. Para Buber - y éste sería el centro de la cuestión, de nuestra lectura al menos - el Tú no representa tan sólo la irrupción del imperativo moral como articulación constitutiva de lo humano, el Tú buberiano hace de aquel encuentro radical la afirmación primaria, incondicional, del mundo. Comprendemos entonces por qué no es privativa del vínculo interhumano, por qué este abrazo del sentido que anuda la existencia como existencia dialogante en la relación con el Tú absoluto tiene diferentes vías de acceso. Nos acercamos al Tú en nuestro encuentro con los animales por ejemplo, porque, en último término, es con el Tú absoluto con quien tropezamos en cada ocasión. El Tú apuntaría hacia el sentido radical de la existencia, hacia el aliento divino, por llamarlo de algún modo, esa bondad de la creación que se derrama sobre el conjunto de los seres creados y sobre las obras del espíritu. "Y vio Dios que era bueno" (Gen. 1: 1-31). Por eso Buber nunca entendió del todo, pienso, el reproche de Levinas y debió haberle parecido innecesariamente rebuscado. En su opinión, la asimetría es una de las formas que puede tomar la relación Yo-Tú, pero no es la única. ${ }^{4}$

La ética, sin embargo, no está fuera de ese encuentro con el Tú, más bien lo supone. En el reconocimiento radical que ocurre entre el yo y el tú humano, acontecen de forma simúltanea la ética y el amor. El amor engendra la ética. Sería inconcebible un amor que no fuera a la vez cuidado y delicada consideración. Pero en algún sentido, el amor

4 "La asimetría es solamente una de las posibilidades de la relación yo-tú, pero no su regla" (Friedman 2006: 64). 
trasciende a la ética. El amor sería más abarcador, se derrama sobre el conjunto de la vida irrigándola con su poder. En la lectura que aquí propongo (y creo que no violento demasiado el elemento religioso del propio Buber), el árbol no constituiría una forma autónoma del Tú, sino que la irrupción de sentido que brota en el encuentro con el Tú absoluto a través del lenguaje (es decir, en la sociedad de los seres humanos) lo impregna y lo significa todo. Entonces, pero sólo entonces, también el árbol, también los perros o las esculturas nos ponen en contacto con la trascendencia. En este sentido, el contacto con la naturaleza o las obras de arte no tendría lugar de manera espontánea y directa, sino que se vería necesariamente atravesada por una relación previa con los demás. El contacto con nuestros semejantes abre la dimensión del sentido y, así, el diálogo con el Tú absoluto de donde brotan la afirmación y la adhesión a la existencia en su nivel más primario. Levinas podría objetar, todavía, que la ética no puede depender del amor (de eso que Kant llamara "inclinación"), de la eventualidad de la simpatía y el reconocimiento, y que, por el contrario, el mandato absoluto que nos impone el otro funda y sostiene al amor.

Sea como fuere, nos parece difícil que la relación con los animales y con las plantas por sí mismas (para hablar de los umbrales del lenguaje que señala Buber) alcanzara para dar cuenta de la significación como tal, es decir, de ese sí incondicional que brota de la confianza básica y el agradecimiento. Es necesario suponer un lenguaje ya constituido, un efecto de significación previa, para que el resto de las relaciones vivan de ese modo "en su luz". La luz del amor que se gesta en el encuentro con el Tú absoluto a través de los otros seres humanos se derramaría sobre las demás criaturas e incluso sobre sus obras. La luz de ese amor brotaría del Yo-Tú fundamental en ese espacio de intersticios donde ocurre el milagro de la respuesta y el diálogo. El testimonio de tal encuentro y la aserción gozosa se derraman sobre el resto de los seres y sobre la existencia entera. Esa aserción elemental, ese sí necesario para que el encuentro fundante sea posible, está antes y después del asombro y la belleza renovada del mundo, pero también antes y después de la guerra, la crueldad, los odios y los tantísimos ejemplos de estupidez y resentimiento que igualmente caracterizan a la especie humana. El Tú buberiano se situaría del lado del embeleso que constituye la vida 
que recibimos y entregamos, de la alegría que confieren la inocencia y la amistad, de la gratitud por el diálogo que nos conforma y a partir del cual somos capaces de entrever el propósito y la especificidad de nuestra condición.

\section{La doble articulación}

Dos eran los árboles que se encontraban en el Edén antes de la Caída: el árbol del conocimiento del bien y el mal y el árbol de la vida. Uno nos haría sabios como Dios, el otro nos daría la inmortalidad. Así como Rosenzweig habla de los tres macizos, Dios, hombre y mundo, entre los cuales fluye y confluye nuestra existencia, y Levinas de la relación Yo-Otro, Buber habla de dos palabras básicas y de dos tipos de relación (Yo-Tú y Yo-eso). Sin la menor duda, todas estas formulaciones son fecundas e iluminadoras en sus contextos; me gustaría, sin embargo, mirar la aventura humana desde la doble articulación que nos plantea la imagen de los árboles y sugerir que allí, justo en el gozne de los significados, puede hallarse la especificidad de nuestra especie desde que Adán y Eva fueran expulsados del Paraíso.

¿Pues qué quiere decir en verdad haber sido expulsado del jardín paradisiaco donde no era necesario saber del bien y del mal? En razón de que sabemos del bien y el mal somos como Dios, dice la Biblia. No sólo semejanza de Dios desde el momento en que Él nos concibiera, sino semejantes al Creador en que podemos distinguir entre los actos que colaboran con su gloria y aquellos que la destruyen. "Socios de Dios", dice la tradición cabalística, en la tarea de procurar la creación y engrandecerla; de recoger las chispas caídas y atrapadas en el sufrimiento, y devolverlas a la fuente de su luz. ${ }^{5}$

Desde el principio de esta configuración poética que es el Génesis, el ser humano tiene una asignación particular, al tiempo que pesa sobre él la obligación de ganarse el sustento con esfuerzo y de parir a sus hijos con dolor. ¿No paren también los animales? ¿No deben transitar a veces grandes distancias para obtener alimento? ¿Por qué constituyen

5 En la cábala luriánica, el mito de la creación. 
estas marcas impuestas a los humanos, marcas que los distinguen del resto de las especies? En el mismo texto, nuestros antepasados más antiguos se vieron desnudos y se avergonzaron. Conocieron su desnudez y tuvieron vergüenza: ¿de qué? ¿De estar expuestos en su precariedad y desamparo? El fruto del conocimiento del bien y el mal nos entregó la conciencia del desabrigo y la mortalidad, y con ella el misterioso destello de comprensión de lo que ha de tenerse por noble y enaltecedor y de lo que envilece y degrada nuestra vida. Por supuesto que no es éste un tema sencillo y aquí empiezan todos los problemas de la ética en los que hoy nos afanamos. Con todo, la expulsión - es decir, la conciencia del desvalimiento radical y de la muerte - parece traer aparejada alguna forma de discernimiento ético y la inteligencia de la necesidad de transformar el mundo para obtener el sustento.

Transformar el mundo ha constituido la estructura íntima de nuestra condición: transformar el mundo para vivir pero, al mismo tiempo, para inscribir en él los principios de justicia que hacen de la Tierra una morada digna de alabanza y de la vida un universo con sentido. Transformar el mundo es al mismo tiempo una circunstancia inevitable (puesto que también los animales transforman su entorno para poder vivir), y la transmutación de esa misma condición en un propósito, en un orden de significado. Para ese orden, transformar el mundo no consiste sólo en obtener alimento, sino en asumir la asignación que nos conmina a sostener el amor a través de nuestros actos bondadosos y a sostener la justicia, la entereza y el valor para que el amor pueda ser continuamente renovado. Renovado siempre. Porque atrás de cada acto de bondad y reconciliación acecha el sinsentido en sus expresiones diversas. "Pues quién soportaría los ultrajes y desdenes del tiempo, la injuria del opresor... las congojas del amor desairado, la tardanzas de la justicia..." exclama Hamlet (Shakespeare 1980: 65), junto a las tantas otras formas del desfondamiento al que está expuesto el sentido que atraviesa nuestros signos. El delicado orden simbólico que habitamos supone que es posible transformar el mundo en lo que tiene de crudeza e impiedad, en uno enaltecido por el llamado de la clemencia y de la rectitud. El mandato de la justicia y el amor sostienen la inocencia y el agradecimiento; los actos de entereza y la respuesta amorosa o responsable permiten que ocurra el diálogo y se renueve la fe en la bondad fundamental de 
la creación. Transformar el mundo es nuestra tarea más noble, aquella que nos conecta con el propósito de elevación moral que hace de la existencia un canto, y nos confiere la dignidad a la que hemos aspirado. Transformar el mundo conforme al llamado de la asignación ética es la huella del enaltecimiento que pesa sobre nuestra especie.

Y sin embargo, el Tú buberiano quisiera ir más allá de esta noble tarea, me parece que no intenta eludirla, naturalmente, pero sí inscribirla en un espectro que al mismo tiempo lo cobija y lo excede. Pues el acontecimiento que representa el encuentro con el Tú en sus distintas formas hace brotar la amistad y así la gratitud, es decir, ese encuentro le confiere a la criatura humana la conciencia plena del mundo como donación y milagro. Gracia y milagro, pero concomitantemente, el "entre" del Yo-Tú, abre el espacio de la plegaria, del contacto secreto con la fragilidad y la oculta interrogación de nuestras vidas. Tal advenimiento excede la acción moral aunque nunca la cancela; es el momento de aserción incondicional, de afirmación vital de la existencia tanto en su bondad última como en sus reveses y sufrimientos. El árbol, los animales y las obras de arte (por mencionar sólo las que Buber considera) pueden también ser puertas hacia esa dimensión. Pero son puertas, como he tratado de sugerir, cuya armazón está engarzada a la conformación ética del lenguaje puesto que allí abrevan su sentido.

Por eso, a diferencia de cualquier otra criatura (al menos hasta donde entendemos ahora), los seres humanos vivimos en el gozne de esa doble articulación: inscritos en la dimensión ética, nos vemos obligados a inscribir nuestra acción en el propósito y a sostener el diálogo que ancla todo sentido. Por otro lado y además de la acción ética misma, pero arropándola, el llamado de la creación entera, en su poder y majestad, nos convoca a asumir plenamente el mundo en su irradiación y misterio. Ninguna de estas dos dimensiones puede ser pasada por alto: ni la acción ética ni la fidelidad primaria a la alegría pueden ser soslayadas o confundidas. Todas las grandes tradiciones se mueven entre uno y otro de estos polos, a veces enfatizando y acercándose a uno de ellos, a veces al otro.

Podemos comprender entonces la crítica de Levinas en el sentido de que Buber ha "estetizado" el estatuto ontológico del hombre en la medida en que el encuentro con el Tú ocurre en ese nivel donde lo estético 
se emparenta con una mística armonía; en cualquier caso, en una relación que no se resuelve como responsabilidad y que, por lo tanto, corre peligro de convertirse en algo interior y narcisista. Como ya decíamos, al final de su vida Levinas cambió su apreciación y reconoció de manera expresa la gran aportación de Buber al pensamiento de la alteridad. Visto, pues, desde el horizonte levinasiano, la pregunta que se plantea es si esa condición dialógica redunda en un mandato ético o deriva en la inclinación producto de la simpatía. Visto desde el horizonte buberiano, la pregunta es si la ética es suficiente para dar cuenta de ese vínculo esencial Yo-Tú que da cauce al amor, a la celebración y la confianza.

Más allá de Buber y de Levinas, pero a través de ellos, la sugerencia que aquí me permito compartir es que la doble articulación del sentido en la que estamos inscritos corre a través de ambas vertientes, de estos dos veneros, entrelazadas del mismo río; escotilla que al abrirse sobre la ética topa con la aceptación plena de la vida como donación y que al encarar dicho sentido en su milagro y asombro, encuentra el mandamiento que brota de la relación con el otro. La alegría del mundo no sería sólo, como supone Levinas, gozo egoísta y consumo. Si el consumo y el gozo están en la base de todo existir, la ética nos inscribe en el lenguaje y el amor. Buber parece implicar que ese amor regresa al mundo bañando la naturaleza, los árboles y las piedras con la fuerza de su luz.

Ésa sería, a mi entender, la invitación del Tú no humano en la filosofía de Buber: vislumbre de los márgenes donde ocurre el sentido, lugar donde el Tú absoluto se derrama sobre el conjunto de lo viviente. “¿Dónde estabas tú cuando yo fundaba la tierra?”, le pregunta Dios a Job. "¿Quién puso su piedra angular/Cuando alababan todas las estrellas del alba/Y se regocijaban todos los hijos de Dios?" (Job: 4, 6-7). El Dios de Job representa la cara oscura de este Dios creador, de este milagro de la creación, pero la reverencia de Job logra advertir en la brutal interpelación que se le hace, el exhorto a recibir la vida en su inmensidad, a afirmarla más allá del enigma insalvable con el que lo golpea. Por su lado Buber contempla al Dios creador en su semblante benévolo, en el punto en el que despliega sobre los campos y las bestias la paz de su bendición.

La creación es más amplia que la vida humana y la fuerza avasalladora de su impulso excede la ley moral. ¿Sería aceptable un orden de 
sentido que apelara tan sólo a nuestra obligación moral al margen de la alegría y el agradecimiento que también nos exige? Sin ellas, la ley moral difícilmente podría irrigar el alma con el candor de la bondad. Por otra parte, un orden que planteara el amor universal pero escatimara la acción moral, ¿sería siquiera digno de ese nombre? ¿No estamos conminados a uno y a otro simultáneamente? Esta permanente dualidad, este doble engranaje por el que fluye el sentido, es el que le confiere envergadura y densidad a nuestra condición dialógica.

\section{En conclusión}

Como se sabe, el Tú no-humano en la obra de Buber apunta al hecho de que todo encuentro Yo-Tú es en realidad un encuentro con el Tú absoluto puesto que todo en verdad vive bajo su luz. Más que panteísmo del que a veces se ha acusado a Buber, se trataría de un panenteísmo donde la divinidad se mantiene trascendente y vierte su aliento sobre todas las criaturas. Hemos sugerido que el llamado a la presencia entre seres humanos abre la dimensión de la trascendencia, y que en la intimidad de aquel "entre" donde nace el lenguaje, se gestan simultáneamente el mandamiento y la alabanza. Ese punto de cruce trabaría el gozne en que organiza el universo significante: por el lado que mira a la ética, a la justicia y al mandamiento, y por el lado que mira a la creación entera como misterio y legado. Dos serían entonces las maneras en que nos situamos en el mundo: "socios de Dios", seres de responsabilidad en la tarea de sostener la entereza con actos de justicia, y, simultáneamente, criaturas capaces de aceptar la vida en su integralidad, de adherirse a ella en la plenitud de su hermosura o desdicha. Pues aun en la congoja somos llamados a la presencia de nuestros semejantes, a la presencia por la que irrumpe el sentido que baña de amor el mundo.

La luz del lenguaje cobija el encuentro con las entidades no humanas; la fuerza de su calor cubre al conjunto de las criaturas. La responsabilidad y la gratitud primera son hermanas gemelas en su seno. Mas no son idénticas. Corren cada una por su cauce exigiéndonos tanto el canto como la tarea, el quehacer como la alegría. La alegría no es, en este sentido, mero gozo, satisfacción egoísta encerrada en su plenitud; es 
también abertura y embeleso, latido del mundo en diálogo con la fuerza primordial del "Tú". Negar alguno de estos dos momentos cercena la experiencia humana y cancela la especificidad de los desafíos que nos regala. En la obra de Buber la ética está presente en el hecho de que el encuentro verdadero con el Tú concibe estos dos gérmenes del significado en el instante mismo del diálogo. La concordia está inscrita en la responsabilidad. Pensar el llamado a la afirmación incondicional como acto de amor que se vierte sobre lo existente, plantea que el sentido pasa siempre por el encuentro con mi prójimo. Y es refrendar, como hace Buber, el juicio divino sobre las posibilidades de generosidad creadora en este acaso breve término que durará nuestro planeta y la vida en ella. ¿No hay aquí una osadía sublime? ¿No hay en esta apuesta por el amor que llena el mundo y por la obligación de honrarlo y de guardarlo, una lealtad a las posibilidades más nobles de nuestra condición? Rehusar alguno de los dos momentos contenidos en el diálogo fundamental conduce a todas las herejías concebibles, sentencia Rosenzweig en esa misma vena: ni el amor ha de vivir sin la obligación, ni la obligación sin la dicha. ${ }^{6}$

Es éste, me parece, el sedimento velado de la propuesta de Buber, uno pocas veces reconocido, pero que muestra el trasfondo de su esperanza y la audacia de su inspiración.

\section{Referencias bibliográficas}

Buber, Martin (2006). Yo y Tú. Buenos Aires, Lilmod.

- (1967). ¿Qué es el hombre? México, Fondo de Cultura Económica.

- (1995). Eclipse de Dios. México, Fondo de Cultura Económica.

- (2014). Caminos de utopía. México, Fondo de Cultura Económica.

Cohen, Arthur A., y Paul Mendes-Flohr (1987). Contemporary Jewish Religious Thought. Nueva York, Scribner.

6 "Es la raíz de todas las herejías humanamente previsibles confundir estas dos mitades del nombre, dejar que el amor se desborde y prevalezca sobre el derecho o el derecho sobre el amor. La función de Dios mismo es reconciliar en sí estas dos potencias, preservar el carácter doble de su nombre, mientras aún exista razón para semejante escisión, mientras no sea Dios el Dios ensimismado fabulado por los filósofos, sino el Dios del hombre y el Dios del mundo" (Rosenzweig 2001: 82). 
Friedman, Milton, Matthew Calarco y Petter Atterton (2006). Levinas y Buber: diálogo y diferencias. Buenos Aires, Lilmod.

Friedman, Maurice (2002). Life of Dialogue. Nueva York, Routledge.

Levinas, Emmanuel (1982). Ethique et Infini. Dialogues avec Phillipe Nemo.

París, Librairie Arthème Fayard at Radio.

- (1999). Totalidad e Infinito. Salamanca, Ediciones Sígueme.

- (2005). Difícil Libertad. Buenos Aires, Lilmod.

Mendes-Flohr, Paul (1996). Ecstatic Confessions. Nueva York, Syracuse University Press.

Putnam, Hilary (2011). La filosofía judía, una guía para la vida. Barcelona, Alpha Decay.

RosenzWeIG, Franz (2001). El libro del sentido común sano y enfermo. Madrid, Caparrós Editores.

- (2007). La estrella de la redención. 2a . ed. Salamanca, Sígueme. 